Article

\title{
The Evolution of Representative Claim-Making by the Chinese Communist Party: From Mao to Xi (1949-2019)
}

\author{
Emilie Frenkiel ${ }^{1, *}$ and Anna Shpakovskaya ${ }^{2}$ \\ ${ }^{1}$ School of Public Administration and International Exchanges, Université Paris-Est Créteil, 94000 Créteil, France; \\ E-Mail: emilie.frenkiel@u-pec.fr \\ 2 Institute of East Asian Studies, University of Duisburg-Essen, 47057 Duisburg, Germany; \\ E-Mail: anna.shpakovskaya@uni-due.de \\ * Corresponding author
}

Submitted: 30 March 2019 | Accepted: 26 July 2019 | Published: 24 September 2019

\begin{abstract}
This article traces the evolution of representative claim-making by the Chinese Communist Party (CCP) since the proclamation of the People's Republic of China in 1949 up to the present day. Based on the analysis of official political discourses on the mass line, the Three Represents and more recent ongoing discourses on digitalization, we demonstrate the change and continuity of claim-making by the CCP. We show that while representative claim-making has undergone a significant transformation from the CCP as the representative of the working class to the sole representative of the Chinese people and nation, the CCP has been consistent throughout decades in maintaining its hegemony over representative claim-making.
\end{abstract}

\section{Keywords}

China; digitalization; discourse; mass line; political representation; representative claim-making; responsiveness

\section{Issue}

This article is part of the issue "Rethinking Representation: Representative Claims in Global Perspective", edited by Petra Guasti (Goethe University Frankfurt, Germany) and Brigitte Geissel (Goethe University Frankfurt, Germany).

(C) 2019 by the authors; licensee Cogitatio (Lisbon, Portugal). This article is licensed under a Creative Commons Attribution 4.0 International License (CC BY).

\section{Introduction}

In this article we analyze the evolution of official discourses on political representation by the Chinese Communist Party (CCP) since the establishment of the People's Republic of China in 1949 up to the present day. Over its 70 years of holding power, the CCP and its discourse on representation have undergone a significant transformation. From the onset of World War II and the civil war against the Nationalists, in a country whose large rural population was extremely poor and illiterate but which is now a rising world power-closer to the century-old nationalist objectives of making China rich and strong, with a strikingly unequal but, overall, a healthier, better educated, more urbanized populationthe CCP has evolved into a massive Party claiming 90 million members ( $6.4 \%$ of the Chinese population). With the unofficial acceptance of entrepreneurs within the Party even before it was officially authorized with the theory of the Three Represents (put forward by former President Jiang Zemin in 2000 and later added to the Constitution in 2002, implying that the CCP represents (i) advanced productive forces, (ii) orientations of advanced culture, and (iii) the fundamental interests of the majority of the Chinese people) and the active recruiting of intellectual elites and talented students ( $80 \%$ of new members are now under 35), the CCP has also moved away from the focus on revolution and class struggle and presented itself as a reformist ruling Party (zhizheng dang) capable of representing the interests of the Chinese people in times of rapid change prompted by technological advancements. In line with these profound socio-economic changes, the CCP has been adjusting its claim to be representative of the Chinese people. 
A key premise of our article is that official discourse should be taken seriously. By official discourse, we mean the most immediate form of political discourse, i.e., "text and talk of professional politicians or political institutions" that "have political functions and implications" (Van Dijk, 1997, pp. 12, 14). The study of official discourses is illuminating as it reveals the official way of thinking, conceptual shifts and evolving aims. Political discourse analysis involves looking at "how politicians think, speak and write about [an issue] and how such discourse and cognition influence political action and hence political structure" (Van Dijk, 1997, p. 42). The Chinese official discourse should therefore neither be ignored as mere propaganda nor simply seen as a description of reality, but should be acknowledged as moulding reality (Li, 2001), as performative and impactful. As Michel Sorace wrote, "for the Chinese state, official discourse and terminology are not merely descriptive; they are also meant to be exemplary and normative, authoritative and binding" (Sorace, 2017, p. 7). As a result, we agree with him that "framing the problem of ideology as a question of belief misses how it functions as an assemblage of practices that shape people's everyday habits of speech and dispositions" (Sorace, 2017, p. 10). In this article, we analyze official discourses attributed to former and current political leaders and which we have identified as explicitly or implicitly focusing on representation. As they are canonical speeches, they can easily be found in collected speeches in print or online.

For analytical purposes, we adopt the perspective of the constructivist turn in the theory of political representation. After Hanna Pitkin published The Concept of Representation in 1967, where she posits the existence of a stable meaning of the concept of representation and the equivalence of political representation with electoral politics, a certain consensus about political representation in English and American political theory emerged (Pitkin, 1972, p. 209). She identifies four different forms of representation: descriptive, symbolic, formalistic and substantive. Some authors have recently challenged the description of political representation as a simple principal-agent relationship between a pre-existing constituency and an elected legislator acting independently but responsively to its constituents, and have enriched the discussion of political representation with new themes (Urbinati \& Warren, 2008). What has been called the "constructivist turn" of political representation (Disch, 2011; Mulieri, 2013; Saward, 2010) focuses on the performative role of representation (what it does rather than simply what it is). Our article aligns with Saward's argument that the interests and identities of the representatives and the rep- resented are not fixed prior to the act of representation, but are constructed through representation (Disch, 2011; Näsström, 2011, p. 506; Saward, 2010). He argues that the focus on electoral forms of representation fails to account for diversified representative claims, which are not only made by elected legislators. With these nonelectoral political practices, spokespersons and different forms of delegation and embodiment emerge. ${ }^{1}$ This constitutive process manifests through representative claimmaking: "a claim to represent or to know what represents the interests of someone or something" (Saward, 2010, p. 305).

To focus on the CCP's representative claims, we find it fruitful to also proceed from the typology of representation developed by Yves Sintomer and inspired by the work of Hasso Hoffman. It encourages us to go beyond the "deceptive familiarity" of representation and its occurrences in English and Romance languages (Sintomer, 2013). According to Sintomer, representation can first be divided into two categories: political-legal and symbolic. Within the category of political-legal representation, the most conventional meaning is mandate representation (acting for), but it also has the meaning of identity representation or embodiment (acting as). ${ }^{2}$ In the framework of embodiment representation, the explicit expression of consent, delegation or further screening from the represented to authorize the representative to speak and act on their behalf is not required. In fact, the representation relationship is supposed to be based on an immediate community of interests, opinions, beliefs and often identity between the representative and the represented. Taking identity representation into consideration is crucial when studying the CCP's claims to represent, as it allows us to understand its claim to political-legal representation despite the absence of direct elections of top leaders. As to symbolic representation, it cannot only take the form of making an absent present (figuration) but also implies the exhibition of a presence, an aspect which Pitkin overlooked (Sintomer, 2013). To complete this typology, Sintomer also highlights the difference between representation as distinction and descriptive representation (Bourdieu, 2001; Gaxie, 1978; Sintomer, 2013, in reference to Manin, 1997), which cuts across the divide between symbolic and legal-juridical conceptions of representation. When representation is conceived as distinction, famously illustrated by Madison (Rossiter, 1961) or Sieyes (1789), representatives are expected to be more capable, wiser and more civic-oriented than the represented. In contrast, when representation is conceived as descriptive, there is a demand for similarity between the represented and the representatives, who must "mirror" (look like) the former.

\footnotetext{
${ }^{1}$ Even though Saward (2010) and De Wilde (2013) only focus on claim-making in democratic contexts, extending this approach to non-democratic cases is acceptable as long as the focus does not switch to the reception of these claims.

${ }^{2}$ As Sintomer (2013) has shown, this last sense of representation is too often overlooked in the theory of representation (including in Pitkin) despite the fact that assimilating the parts to the whole (pars pro toto) was a recurrent conceptualization of representation in the European Middle Ages, which has left its mark on more modern conceptualizations of political-legal representation. Indeed, it is blatantly present in the case of charismatic leaders, whether monarchical, self-appointed or democratically elected, but also in some conceptions of parliament (Burke, 1949) and even in radical democratic experiments like the Occupy movement (with the famous slogan "We are the 99\%").
} 
Figure 1 summarizes the typology of political representation offered by Sintomer.

As presented in the figure, distinction, description and substantive forms are individual categories that are applicable to the realization of both political-legal and symbolic representation. It is thus possible, for example, that symbolic representation is manifested through distinction to achieve the substantive effect of representing. Different combinations are therefore possible. It must be also noted that these are ideal types that may often overlap in real politics. This being said, we consider this typology to be useful for deconstructing and analyzing different nuances and forms of representative claims.

We break down selected texts into the components from Saward's model of claim-making, as in the following example: "A Maker (M) puts forward a Subject (S) which stands for an Object (O) that is related to a referent (R), e.g., content of representation and is finally offered to an Audience $(A)$ " for tracing and analyzing the evolution of the CCP's representative claim-making over several decades. In the discourse we study, we find that on the one hand the claim-maker (M), the CCP, has been positioning itself as the sole representative (the subject (S) of representation) of the interests of the Chinese people (object (O)), often by suppressing alternative representative claims. Under the influence of Lenin's vanguard Party concept, the CCP combined representative claims pertaining to both political-legal (identity) and symbolic representation, with alternative claims of descriptive distinction representation and above all substantive representation.

On the other hand, the CCP has been adjusting its claims of representation to the rapidly changing realities and trying to improve its capacity to respond to the interests of the people. At the turn of the millennium, the official discourse becomes more openly elitist and technocratic to improve substantive representation (performance). Another object of the representative claim surfaces, namely the nation (which should be richer and stronger), but it tallies with the still prevalent claim to represent all the Chinese people. To make the elitist evo- lution acceptable, the traditional Maoist method of the mass line (the mass line-qunzhong luxian in Chineseis the guiding method, formulated by Mao Zedong in 1943 , of consulting the masses, collecting their opinions and eventually formulating them into state policies) is updated on the basis of diverse forms of consultation. While the discourse on consultation of the masses has always been present, it has intensified and these devices compensate, at least symbolically, for the more explicit guardianship discourse (representation as distinction). Consultation is related not only to symbolic but also to substantive representation as a convenient way to identify the urgent problems that need solving and thereby maintain the image of the Party as the best representative of the Chinese people's and the nation's interests.

The article consists of five parts. Following the Introduction, we outline the dynamics of representative claim-making in authoritarian China. We then focus on discourses on the CCP's continuous but evolving hegemonic claim to represent the Chinese people over five generations of leaders. In the fourth part, we discuss the implications of the new information and communication technologies (ICTS) and digitalization for political representation in China. We summarize our findings in the conclusion.

\section{The Dynamics of Representative Claim-Making in China}

Despite the existence of various formal and informal, topdown and bottom-up channels for interest expression in China (Heberer, 2016), the Chinese context is characterized by the prevalence of the CCP's persistent hegemonic claim-since the proclamation of the People's Republic of China in 1949 and throughout the five generations of the CCP leadership - to represent the fundamental interests of the majority of the Chinese people.

As the sole representative of the majority of the people, the CCP performs three main tasks. First, it is expected to respond to people's needs. Mao's famous 1944 slogan "Serve the people" (wei renmin fuwu) is still one

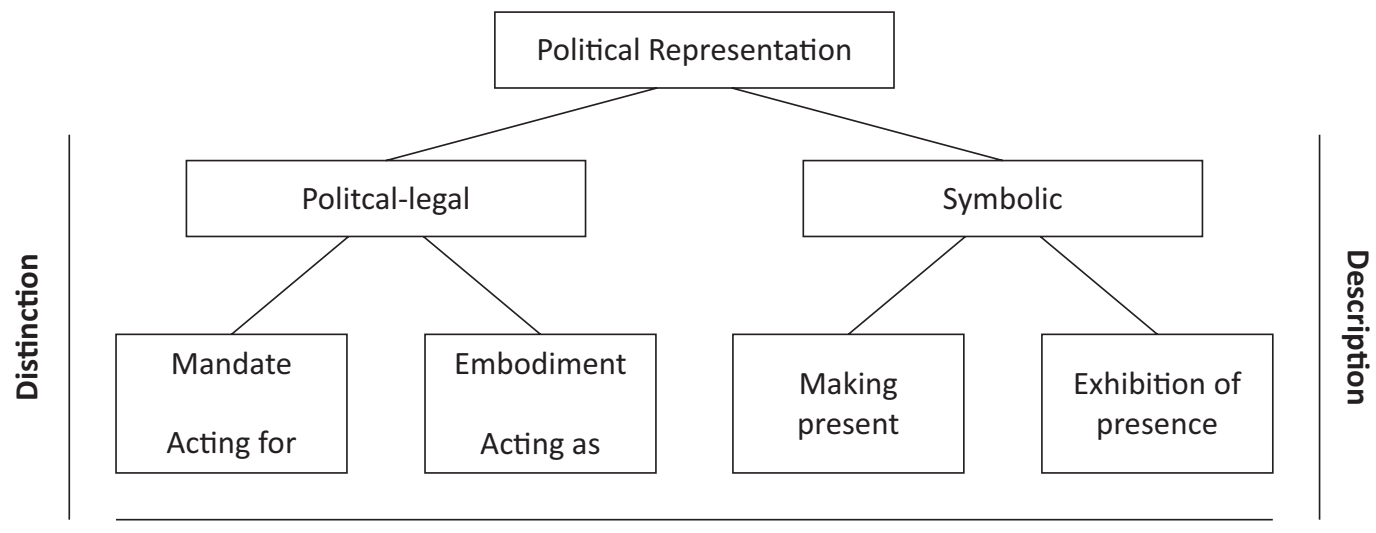

Substantive

Figure 1. Categories of political representation. Source: The authors. 
of the Party's main claims and Xi recently stated that "wholeheartedly serving the people has been always the fundamental goal of the Party and the main reason why our Party is supported and loved by the people" (Renmin Ribao, 2015). This can be interpreted as a substantive representative claim, as, according to Hannah Pitkin's definition, representation is a "substantive acting for others" and "acting in the interest of the represented, in a manner responsive to them" (Pitkin, 1972, p. 209). The Party has therefore striven to legitimize itself through depicting itself as a better representative of people's interests than conventional elected representatives in the West (in "formal democracies") because of the substantive representation (and therefore supposed "substantive democracy") it achieves (Frenkiel, 2015) through the delivery of a long-term perspective and tangible results, like military victories, women's liberation and collectivization in its first period and after Mao's death, economic performance, poverty alleviation, "small prosperity" (xiaokang), infrastructure building, regaining power on the international scene, becoming an innovative nation and so on.

In connection with these objectives and achievements, the Party's second task is to identify core national interests, which are formulated in major speeches and reports (five-year plans, Party congress reports). Thirdly, given the pluralization of society and of interests resulting from the growing gap between those who have benefited most from the Reform and Opening Policy launched in 1978 and the others, the CCP acts as a coordinator of various and often conflicting interests of different social groups with the main goal of maintaining social stability (weiwen). This goal has been blatantly officialized under Hu Jintao's "building a harmonious society" (jianshe hexie shehui) slogan. Social stability and subordination of individual interests to collective national interests have been the fundamentals of the CCP's vision of political representation. However, with the Party's transformation to a ruling Party, forsaking class struggle, conflictuality has been gradually erased and politics conceived as a series of problems needing to be identified, then solved consensually and scientifically (as illustrated by slogans such as "scientific socialism" and "scientific governance") by a well-trained technocratic elite (Li, 2009) selected through meritocratic principles (Bell, 2015; Gore, 2019), and surrounded by the best experts (Frenkiel, 2015). In this apoliticized conception of politics, the CCP depicts itself as a neutral arbiter, never defending its own interests but only the people's and the nation's (He \& Yao, 2011). In other words, as Demin Duan (2019) writes in an article on the CCP's representative turn from vanguard to representative published in this special issue, with the theory of the Three Represents, the CCP shifts from a revolutionary vanguard conception of representation (letting people be aware of their own historical mission and be able to rule themselves) to a more technocratic and elitist understanding of representation that places the representatives above the represented.

\section{The Evolution of the CCP's Hegemonic Claim from Mao to Xi (1949-2019)}

In official discourse, the focus is put on substantive representation, as representation is often defined as the capacity to be responsive and responsible. To display representativeness (the capacity to represent the majority), the Party-state must demonstrate its responsiveness to and responsibility for the needs and interests of the people. The evolution of the discourse on the mass line is a case in point; so too are the current official discourses on digitalization.

The traditional conception of representation by the CCP derives from Lenin's conception of the Party as the vanguard of the working class. Mao innovated by including the peasants, whom he tended to glorify, in the revolution and recruited them to political offices after 1949. The vanguard role assumed by the Leninist Party rests upon two assumptions: first, that a single Party is capable of representing the interests of the working class as a whole without a critical opposition to help it avoid and correct omissions, inaccuracies and mistakes; and, second, that the vanguard is capable of speaking in a single, united voice for those it claims to represent, in the absence of competition (Geras, 1981; Thornton, 2016).

Even though the word daibiao (represent) does not appear in Mao's speeches theorizing the mass line, this theory helps us understand how the Leninist concept of representation by the vanguard Party was applied to the Chinese context. Mass line theory (qunzhong luxian) was first formally expounded in war times in "Some questions concerning methods of leadership", a resolution written by Mao and adopted by the Central Committee on 1 June 1943. The resolution formalizes practices which communists had more or less consciously adopted for the leadership (cadres) to connect with the masses. Mao considered the mass line as one of the main work methods of the Party, based on the principle described as "all for the masses, all depend on the masses, from the masses and among the masses" (yiqie weile qunzhong, yiqie yikao qunzhong, cong qunzhong zhonglai, dao qunzhong zhongqu). Specifically, this method consists in ensuring that leaders are never "cut off from the masses" and constantly reconnect with them through three main functions: collecting and distilling popular perceptions/interests, avoiding bureaucratism and elitism, and educating the masses for them to finally no longer need leaders when they become fully capable of ruling themselves. The mass line is therefore based on the absence of a presumption of ordinary citizens' personal autonomy.

The mass line was also explicitly presented in a speech entitled "Organize!" that Mao gave on 19 November 1943 in which he forbids senior cadres and militaries to be cut off from the masses. The idea conveyed in that speech is similar to Liang Qichao's idea at the end of the 19th century to tap into the Chinese people's will and formidable latent energy to strengthen 
the nation. Mao uses the image of Zhuge Liang (one of the most brilliant strategists in Chinese history, who lived during the Three Kingdoms period), whose like can supposedly be found in every Chinese village, to convey a non-elitist conception of the people's capacities. Through education and propaganda, leaders impose policies that they derive from the needs that the masses themselves express, albeit confusingly. With the mass line, Party cadres are to promote policies put forward by a vanguard Party whose distinction and wisdom are urgently needed to transform and distil amorphous public opinion into policies benefiting the Chinese people in the long run. Even though Mao emphasized democracy, implicitly, it seems that we are close to what Robert Dahl called the "guardianship discourse" (Dahl, 1989) in the sense that only an especially qualified elite can govern for the common good (Manion, 2015, p. 86). Mao, however, insists on the right proportion of responsiveness necessary for this representation to be substantive and not just symbolic (Frakt, 1979). The representatives are supposed to sincerely listen and learn from ordinary citizens, respond to them and translate their raw opinions into political decisions. The Party line is dictated neither by the people nor the Party cadres, who are merely messengers because, as Hanna Pitkin wrote on the intermediary spectrum of representation, "a man who merely consults and reflects without acting is not representing in the sense of substantively acting for others" (Pitkin, 1972, p. 211). The traditional vanguard Party conception, which is central to the CCP's representative claim and its application in the mass line, therefore combines identity representation, descriptive representation and representation as distinction (Sintomer, 2013). The Party is not a separate caste outside of the people but rather a pars pro toto. The mass line and the vanguard Party are therefore framed as democratic. Party cadres are selected among and act as the working class and the peasants (identity representation) and are like them (descriptive representation). They are not an aristocratic elite, but are nevertheless presented as more capable than ordinary citizens, speaking both like them and better than them (distinction).

Deng Xiaoping further maintained that the interests of the people should be placed above everything else and suggested four criteria (in the form of questions) that determine a policy's success: Is the policy approved by the people? Is it supported by the people? Does it make people happy? Do the people promise to endorse it? (Renmin Ribao, 2014). This, at least in theory, suggests an active role for the people in legitimizing the CCP's function as the sole representative. Deng further pointed out:

What's good about having the multi-Party system of capitalist countries? The multi-Party system is a result of the mutual struggle among bourgeois groups that can never represent the interests of the vast working masses of the people. There are multiple parties in our country too, but they all serve the socialist cause under the premise of acceptance of the CCP's leadership. (Zhong, 2009)

Both Mao and Deng viewed representation of the collective interests of the people as a fundamental mission of the Party and its representative capacity as an essential guarantor of social justice and stability. The CCP as the main and the only representative also sought validation from the people. At least in theory, the people could approve or disapprove the policies by streaming their voices through carefully designed and managed official channels. The mass line pertains to this process. The administration of letters and visits (xinfang) created in 1951 has also been "responsible for receiving, registering, and forwarding testimonies and requests to the concerned parties" (Hua \& Thireau, 2010) and has provided a fundamental mechanism at all administrative levels for a wide range of individuals and groups to expose injustices, embezzlement, or the faulty application of administrative procedures. It was the sole channel for the Chinese people to voice their discontent until the 1980 s, and is still used by people to this day. The digitalization of the bureaus (especially with the creation of websites and accounts on social media) has greatly facilitated access to their services. Finally, even though the media are considered to be the mouthpiece of the CCP, since 1987 and liberal-leaning Zhao Ziyang's reference to "control by the media" or watchdog journalism (yulun jiandu) in the political report he delivered at the 13th Party Congress, the idea of the media as compelling the authorities to be more transparent and providing communication channels between the Party and the people has been present in official speeches, albeit in a more or less toned down manner depending on the context (Repnikova, 2018; Salmon, 2011).

This logic of representation was also maintained in the post-Deng era. Jiang Zemin's pivotal "Three Represents" theory, ratified at the 16th Party Congress in 2002, is the leading example of the CCP's adaptability to the new realities and new challenges for representation. Since the Reform and Opening Policy was launched in 1978, Chinese society had transformed and diversified, with new social groups emerging and demanding that their voices are heard and interests addressed. Rather than suppressing new demands for representation and provoking social dissatisfaction and unrest, the CCP absorbed and integrated them into its own system. With the Three Represents, the object of representation (O), the people who the CCP is supposed to represent, no longer refers only to the working class and the peasantry but also includes capitalists, which is a major change in discourse (even though in practice, changes occurred before the theory was announced). By absorbing the new (elite) representative social forces, the CCP successfully preserved its status as a hegemonic representative of the interests of the majority of people. Thus, the capacity to represent the majority has been seen by the CCP top leadership as the source of the Party's legitimacy, sur- 
vival and continuity. For example, in one of his speeches in 2000 Jiang Zemin stated:

The reason our Party enjoys the people's support is that throughout the historical periods of revolution, construction and reform, it has always represented the development trend of China's advanced productive forces, the orientation of China's advanced culture, and the fundamental interests of the overwhelming majority of the Chinese people. (China Daily, 2010)

The so-called fundamental interests of the people include economic, cultural and political interests. By representing "advanced productive forces", the Party represents the economic interests of the people. By representing the orientation of advanced culture, the Party claims to represent the cultural interests of the people (development of creativity, mind and spirit). Finally and most importantly, the Party also claims to represent the political interests of the people by guaranteeing that the people remain the true and the only master of the country (renmin dangjia zuozhu).

In a similar vein, Hu Jintao emphasized:

Our Party is the Marxist ruling Party. All tasks and responsibilities of the Party are for the benefit of the people's interests. To represent the fundamental interests of the majority of the people...has been consistently the guiding thought of four generations of leaders in our Party. (Wu, 2006)

As a result, since the Three Represents, the Party still considers itself as a vanguard Party even though it no longer claims to represent the proletariat alone but the whole Chinese people and nation. As reflected in the revisions to the Constitution adopted in November 2012 during the 18th Party Congress:

The Communist Party of China is the vanguard both of the Chinese working class and of the Chinese people and the Chinese nation. It is the core of leadership for the cause of socialism with Chinese characteristics and represents the development trend of China's advanced productive forces, the orientation of China's advanced culture and the fundamental interests of the overwhelming majority of the Chinese people. (Constitution of Communist Party of China, 2012)

The Party has metamorphosed and adapted to new domestic and international social and economic conditions (Shambaugh, 2008). In order to legitimize itself and to curb its ideological crisis, the Party has sought to demonstrate not only continuity but also its efforts to adapt to changing contexts and reform. It strives to show itself as the only possible guarantor of the country's interests, development and stability, while remaining in touch with social realities (Cabestan, 2014, p. 58). China's economic and diplomatic rise on the international stage has helped to legitimize these claims while rising inequalities have weakened them. The ubiquitous campaigns against corruption and poverty are framed to counter the view that past reforms have not benefited the whole population equally and that officials are cut off from people's needs. They are more or less explicitly reminiscent of the mass line.

$\mathrm{Xi}$ Jinping, for his part, has placed emphasis on improving the formal institutions of political representation, such as people's congresses and political consultative conferences. In his speech at the 19th National Congress of the CCP in 2017, in addition to drawing attention to the traditional definition of people's congresses as organs of power (quanli jiguan), he stressed that people's congresses should better perform their representative function and eventually become organs of representation while maintaining a close connection to the masses (Xi, 2017). Undoubtedly, the Chinese leadership sees digitalization as one of the sources of improvement of its representative capacity. For example, in 2016 Xi Jinping demanded that all Party and government cadres should follow the people's demands online, should learn how to use the internet to hear the needs of the people, collect "benign" opinions and suggestions and respond to the concerns of the people (Zhou, 2016). In June 2016, the Central Leading Group for Comprehensively Deepening Reforms, led by Xi Jinping, adopted "Suggestions on improving implementation of closer ties between the National People's Congress (NPC) representatives and the masses". The "Suggestions" require the establishment of new and well-functioning online platforms for improving the connection between the people and NPC representatives. The document also calls for the establishment of multiple channels for people's representatives to express public opinions more effectively (Wang, 2017).

Another interesting development that we have been observing in China in recent years is personification of representation or what Yves Sintomer labels embodiment representation (Sintomer, 2013). From official rhetoric, we can see that representation is presented to the public as the major mission not only of the Party but of the Party chief himself. Xi Jinping is often portrayed by the state media as the true representative of the people (renmin daibiao Xi Jinping) and the story of Xi's rise from the grassroots (his father was a senior general but the family was persecuted during the Cultural Revolution) to highest leadership level has arguably been depicted as appealing to people. Official commentators have interestingly framed the reason why Xi's Thought has supposedly become popular among the people in reference to representation. His popularity is said to be mainly due to his capacity to represent the needs of the people and respond to their claims (Liang, 2018). Given the strict authoritarian context, the popularity of the president and the CCP's claims are hard to verify. We can nonetheless hypothesize, if confirmed, the efficiency of tightly controlled communication and a drilled narrative presenting 
$\mathrm{Xi}$ as the saviour combining representation as distinction and embodiment representation. He is presented as having started from zero (during the Cultural Revolution), being a simple man (eating and talking simply) and knowing the common people (laobaixing) well, a strong and seasoned but benevolent ruler ( $x i$ dada) willing to make tough decisions to redress other officials' lack of rectitude and responsiveness. This narrative frames $\mathrm{Xi}$ as the embodiment of a strong and modern China, the right ruler to lead China towards further modernization (having been in charge of one of the most modern and developed province in the past) in the age of digitalization.

\section{Digitalization and Political Representation}

Speedy proliferation of the ICTs and particularly social media in China stimulated the creation of online spaces for bottom-up self-expression (Han, 2018b), online activism and alternative opinions (deLisle, Avery, \& Yang, 2016; Frenkiel \& Wang, 2017; Yang, 2009; Zheng, 2007). This also allowed different patterns of representation and representative claim-making to emerge (Heberer \& Shpakovskaya, 2017, 2018). Since the introduction of Weibo in 2009, the platform has become the largest and most important space for public debate, including contestation of official discourses on representation in China. In the past five years, however, the Party-state has been consistently introducing tougher regulations and censorship practices to monitor and control dissemination of information and fake news and to guide public opinion, thereby affecting the platform of most relevance to the issue of claim-making. Weibo microblogging provided intellectuals with an opportunity to publicly express their individual opinions on the state of representation and make claims relating to representation and misrepresentation (Shpakovskaya, 2018). Popular microbloggers are key opinion leaders who are followed by millions of fans. The most critical ones have been systematically censored and blocked by the authorities. Thus, we argue that a previously freer online space that allowed public debate on political representation and claim-making has gradually become dominated by the Party-state that vigilantly maintains its position as sole representative of the Chinese people and their interests.

In the following passages, we demonstrate the discourse on the ICTs and digitalization that the CCP has been promoting online and offline. More specifically, our analysis of Xi Jinping's official speeches from 2014 to 2018 shows that digitalization is often presented by the leading authorities as both a prerequisite for development and a potential source of social instability and crisis. As the sole representative of the "people's fundamental interests" as well as of "new productive forces" and "advanced culture", as claimed in the Three Represents, the CCP has been actively attempting to se- cure the leading role in the process of modernization through digitalization.

\subsection{Digitalization as a Prerequisite for Socio-Economic Development}

The Party-led transformation of China into a digital superpower (wangluo qiangguo), first proposed by Xi Jinping in 2014 , had become, by 2018 , one of the leading strategic thoughts (zhanlve sixiang) of new development (xinxing fazhan). ${ }^{3}$ In official speeches, digitalization and the new ICTs are presented to the public as an unprecedented opportunity for promoting China's rapid development. In the most recent version of this well-established trend, digitalization-according to Xi Jinping-"represents new productive forces and the direction for new development" (Renmin Ribao, 2018). First and foremost, digitalization is seen as an opportunity for economic growth driven by technological innovations. Technological innovation in artificial intelligence, big data management and innovative initiatives by small and medium-sized businesses are thus all considered essential for the overall economic modernization of the country.

Furthermore, a new notion of a "smart society" (zhihui shehui) was put forward by Xi Jinping in 2018. Deriving from the concept of the "smart city", building a "smart society" is the ultimate goal of digitalization. No clear-cut definition has been yet spelt out; however, the notion boils down to the general idea of an equal society enabled by digital technologies. This equality, e.g., equitable economic development based on mutual aid between rich cities and poor countryside and equal access to social welfare, can supposedly be reached by narrowing down digital gaps between cities and villages and between different social groups (Shan, 2018). It is also emphasized that a "smart society" must manifest socialist values and be appropriate for Chinese national specificities. The goal, then, is not simply to mimic foreign models: in a smart society, "individual interests must fuse with national interests and priorities in order to achieve the third millennium goal-the building of a smart society with Chinese characteristics" (Li \& Zhang, 2017).

In addition, Xi Jinping strongly encouraged government officials and people's congress deputies to revive the traditional mass line by actively engaging with the public online. At the Work Symposium on Cybersecurity and Informatization in 2016, for instance, he demanded that in the spirit of the mass line, all Party and government cadres should follow the people's demands online. Xi stressed that:

Netizens come from the people; when people go online, their will and expectations also go online. Our leading cadres should follow the people. Party cadres should learn how to exercise the mass line on the in-

\footnotetext{
${ }^{3}$ The concept of "a digital or cyber superpower" was first proposed in 2014. Later, in 2015, the concept was further developed in the Internet Plus Action Plan proposed by the central government. In 2018, Xi Jinping put forward the concept of "Strategic Thought on Cyber Superpower" (wangluo qiangguo zhanlve sixiang), which is considered a further theoretical development of the framework for cyberspace governance and cybersecurity in China.
} 
ternet. They should often go online, learn what people think and want, collect good thoughts and opinions and actively respond to the people's concerns and doubts. Let the internet become a new channel for understanding and listening to the masses, for solving the problems of the masses, for nurturing democracy and for subjecting ourselves to supervision by the people. (Renmin Ribao, 2016)

The above extracts have two important implications. On the one hand, the Party-state has been actively adapting to the changing environment stimulated by the ICTs. By appropriating the ICTs for better and more efficient social service provision, the CCP aims to recreate and reemphasize its image and function as the sole representative of the people. By promoting the idea of the digital mass line, the CCP aims to enhance its bond with the people by demonstrating its closeness to the hearts and minds of the people through the use of ICTs. This may be interpreted as a form of mixed symbolic representation combining descriptive representation and politics of presence where the CCP acts as a representative that demonstrates similarities with and closeness to the represented.

E-governance may potentially contribute to the CCP's ability to better identify and respond to the interests of the people and thus improve its capacity for substantive representation. On the other hand, the consistent reference to conventional notions such as the mass line and Party's leadership also suggests that the CCP adheres to the idea of consultation and responsiveness as parts of representation through channels that are tightly controlled by the CCP and that it has no intention of weakening its monopoly over representation.

\subsection{Digitalization as a Source of Instability and Risk}

Digitalization and new ICTs are not only depicted as the driving force for socio-economic modernization and development, but are also highly associated with instability and crises. In the official discourse, they are often presented as a source of digital crime, fraud, falsified information, pornography and potential cause of chaos. Therefore, the greatest attention has been paid to preserving cybersecurity. Moreover, cybersecurity is continuously equated with state security and directly linked to the interests of the people that the CCP is to represent. $X i$ Jinping emphasized that "without a secure cyberspace, there can be no secure state or stable economy, and the interests of the overwhelming majority of the people thus cannot be guaranteed" (Renmin Ribao, 2018).

Most importantly, the Party defines cyberspace security and management as its foremost responsibility to the nation and the people: "We must strengthen our cyberspace governance in accordance with the law and with an attitude responsible to the society and the people" (Cyberspace Administration of China, 2016).

In addition to cybersecurity, another notable development is the call to actively create a safe and posi- tive online ecology. The cyberspace is often criticized by authorities for being too negative (link with previous quote's "good opinions") and aggressive. This negativity and aggression are considered unhealthy and are thus in conflict with the interests of the netizens, particularly the younger internet users. The internet should therefore be cleaned up by spreading positive energy (zhengnengliang):

It is necessary to enhance the construction of online content, its positive propagation online, also to nurture a positive and healthy online culture that encourages aspirations toward improvement and goodness. It is necessary to nourish the people's hearts and society with core socialist values and outstanding achievements of human culture. It is important to ensure abundance of positivity in order to create for the internet users, and young users in particular, a cyberspace that is clean and healthy. (Cyberspace Administration of China, 2016)

To fulfil its responsibility as the main guarantor of cybersecurity and positive online ecology, the Partystate has made efforts aimed at (1) regaining its central presence in the cyberspace by establishing official platforms for dissemination of official narratives and online communication with the people (King, Pan, \& Roberts, 2017); (2) building up a professional team of cyberspace managers; (3) improving the regulatory framework; and (4) tightening online censorship and enacting self-censorship (King, Pan, \& Roberts, 2013). Most notably, as some researchers have shown, the creation of a positive and ideologically correct online environment is not only a product of tightening censorship and coercion, but is also a result of persuasion (Repnikova \& Fang, 2018), negotiation (Jiang, 2016), and active online engagement of pro-regime netizens ( $H a n, 2018 a$ ) and nationalists (Schneider, 2018).

From the representation perspective, the CCP certainly positions itself as the sole capable representative of the people's interests, e.g., it is the CCP that possesses the necessary capacity to deal with the emerging danger brought about by digitalization. It claims to be the guarantor of safety and order. That is in line with representation as distinction, discussed above, and with substantive representation. To achieve its goal of being the sole representative, the CCP has been suppressing alternative claim-makers, such as outspoken bloggers, in the name of a safe and stable online environment. At the same time, however, the CCP has been actively penetrating the internet by establishing a wide net of websites for e-governance aimed at better social service provision through consultation.

\section{Conclusions}

To better understand the nature of political claimmaking, we used Yves Sintomer's ideal types to go be- 
yond the "deceptive familiarity" of representation and its occurrences and analyze the official conceptualization of representation in China in light of this typology. We have seen that his concept of embodiment representation (acting as) allows us not only to approach the CCP's representative claims in terms of symbolic representation (descriptive representation and politics of presence) and substantive representation (acting for), but also to grasp its political-legal dimension despite the absence of direct elections of top leaders.

Applying discourse analysis, we examined the evolution of the CCP's representative claim-making since 1949 to the present day and draw the following conclusions. First, there has been a continuous upgrading in conceptualization of representation and expression of representative claims by the CCP leaders. This is revealed in the Three Represents, as well as in the recent speeches of Xi Jinping. Not only has the CCP diversified the formulation of who it represents (the object of representation), but it has also raised the significance of representation by referring to representation as the Party's duty and responsibility, aimed at improving its capacity to represent substantively. More specifically, we showed that in the Chinese official discourse, the focus has gradually been put on substantive representation as the CCP has often presented itself as a performance-driven Party acting in a responsive way. To display representativeness (the capacity to represent the majority), the Party-state must demonstrate its responsiveness to and responsibility for the needs and interests of the people. In pursuing this aim under Mao, the CCP tended to employ both the elements of representation as distinction and description. After the Three Represents and its elitist turn, claims of symbolic representation have been more vigorously combined with claims of substantive as well as identity representation. Our analysis of the evolution of the discourse on the mass line and the current official discourses on digitalization both exemplify this dynamic. Since the Party leadership has gradually considered the interests of the Chinese people as more diverse and less objective, it has indeed presented itself as a neutral arbiter and relied more extensively on popular consultation, without yielding anything of its claim to represent, which is in line with Pitkin's emphasis on the role of consultation in substantive representation.

Secondly, alongside changes in discourse, we also trace continuity. We contend that over decades, political representation has invariably been perceived by the CCP as the capacity to represent the interests of the majority of the Chinese people. Most importantly, the CCP has been positioning itself as the sole representative of the Chinese people. In the age of fast proliferation of the new ICTs, the CCP has adjusted its discourse on digitalization by presenting it as both a prerequisite for development and a source of chaos. That is how the CCP attempts to justify its increasing control over the internet: it is supposedly the duty of the sole representative to maintain stability and make the most of the use of new technolo- gies in the interests of the Chinese people and the nation. We argued that to fulfil its responsibility as the main guarantor of cybersecurity and positive online ecology, the Party-state has enhanced its online visibility as well as tightened its control over alternative claim-makers that emerged online. We thus conclude that alongside improving the CCP's governing capacity and substantive representation with the use of digital technologies, the conventional representation dynamics, where the CCP has been maintaining its monopoly over representation, remains predominant.

To sum up, over past decades the CCP has been adjusting its representative claim to the rapid socioeconomic transformations reshaping the country by moving from the Leninist and Marxist ideals of representation of workers and peasants in the continuous class struggle and positioning itself as a Party that represents the interests of the Chinese people and the future of the nation. We demonstrated how the CCP has embraced various strategies over the decades, emphasizing elements of political-legal (mandate and embodiment) and symbolic representation as well as distinction and description representation. We also highlighted a shift in the focus of representation from symbolic to substantive, mainly through digitalization of the mass line and consultation. Finally, we showed how social media in China have provided a platform for bottom-up claims on representation and misrepresentation. By promoting itself as the sole capable representative of the national interests and guarantor of security in the digital age, the CCP attempts to legitimize its intolerance towards alternative claim-makers and preserve its hegemony over claim-making.

\section{Acknowledgments}

Both authors contributed equally to this article. The authors would like to express their sincere thanks to the guest editors Petra Guasti and Brigitte Geissel for their constructive comments and suggestions to improve the quality of the article, as well as to the two blind reviewers. The authors are also grateful to the German Research Foundation (DFG) and French Research Agency (ANR) for generously funding their research for this article as part of the French-German Joint Cooperation Project "New Political Representative Claims: A Global View-France, Germany, Brazil, China, India Compared (2016-2019)".

\section{Conflict of Interests}

The authors declare no conflict of interests.

\section{References}

Bell, D. (2015) The China model. Princeton, NJ: Princeton University Press.

Bourdieu, P. (2001). Langage et pouvoir symbolique [Language and symbolic power]. Paris: Seuil. 
Burke, E. (1949). Speech to the electors of Bristol. In R. J. S., Hoffman \& P. Levak (Eds), Burke's politics, selected writings and speeches. New York, NY: Knopf.

Cabestan, J. P. (2014). Le système politique chinois. Un nouvel equilibre autoritaire [The Chinese political system. A new authoritarian balance]. Paris: Presses de Sciences Po.

China Daily. (2010). Three Represents. China Daily. Retrieved from http://www.chinadaily.com.cn/china/ cpc2011/2010-09/08/content_12474313.htm

Constitution of Communist Party of China. (2012). Constitution of Communist Party of China. China.org.cn. Retrieved from http://www.china.org.cn/china/18th_ cpc_congress/2012-11/16/content_27138030.htm

Cyberspace Administration of China. (2016). Xi Jinping zongshuji zhuchi zhaokai wangluo anquan he xinxihua gongzuo zuotanhui qiangdiao: Rang hulianwang genghao zaofu guojia he renmin [General Secretary Xi Jinping presides at a symposium on cybersecurity and digitalization: Emphasizing the Internet to better benefit the country and the people]. Cyberspace Administration of China. Retrieved from http://www. cac.gov.cn/2016-08/15/c_1119330260.htm

Dahl, R. (1989). Democracy and its critics. New Haven, CT: Yale University Press.

deLisle, J., Avery, G., \& Yang, G. (Eds.). (2016). The internet, social media, and a changing China. Philadelphia, PA: University of Pennsylvania Press.

De Wilde, P. (2013). Representative claims analysis: theory meets method. Journal of European Public Policy, 20(2), 278-294.

Disch, L. (2011). Toward a mobilization conception of democratic representation. American Political Science Review, 105(1), 100-114.

Duan, D. (2019). On authoritarian political representation in contemporary China. Politics and Governance, 7(3), 199-207.

Frakt, P. (1979). Mao's concept of representation. American Journal of Political Science, 23(4), 684-704.

Frenkiel, E. (2015). Conditional democracy. London: ECPR Press.

Frenkiel, E., \& Wang, S. (2017). Les jeunes Chinois dans différents espaces nationaux: Expressions et engagements politiques [Young Chinese in different national spaces: Political expressions and commitments]. Participations, 17(1), 5-33.

Gaxie, D. (1978). Le cens caché [The hidden census]. Paris: Seuil.

Geras, N. (1981). Classical Marxism and proletarian representation. New Left Review, 1981(125), 75-89.

Gore, L. (2019). The Communist Party-dominated governance model of China: Legitimacy, accountability, and meritocracy. Polity, 51(1), 161-194.

Han, R. (2018a). (Un)civil society in digital China | Withering Gongzhi: Cyber criticism of Chinese public intellectuals. International Journal of Communication, 2018(12), 1966-1987.

Han, R. (2018b). Contesting cyberspace in China: Online expression and authoritarian resilience. New York, NY: Columbia University Press.

He, D., \& Yao, Y. (2011). Shehui pingdeng, zhongxing zhengfu yu zhongguo jingji zengzhang [Social equality, neutrality of government and economic growth]. Jingji Yanjiu, 2011(1), 4-17.

Heberer, T. (2016). Reflections on the concept of representation and its application to China (Working Papers on East Asian Studies, Institute of East Asian Studies, University Duisburg-Essen). Duisburg: University Duisburg-Essen.

Heberer, T., \& Shpakovskaya, A. (2017). The digital turn in political representation in China (Working Papers on East Asian Studies, Institute of East Asian Studies, University Duisburg-Essen). Duisburg: University Duisburg-Essen.

Heberer, T., \& Shpakovskaya, A. (2018). Shuzihua jishuxia zhengzhidaibiao zhuanxing: Zhongguode anli ji qi lilun yiyi [The transformation of political representation through digital technologies: The case of China and its theoretical implications]. Guowai lilun dongtai, 2018(10), 68-77.

Hua, L., \& Thireau, I. (2010). Les ruses de la démocratie: Protester en Chine [Democracy's tricks: Protesting in China]. Paris: Seuil.

Jiang, M. (2016). Managing the micro-self: The governmentality of real name registration policy in Chinese microblogosphere. Information, Communication and Society, 19(2), 203-220.

King, G., Pan, J., \& Roberts, M. E. (2013). How censorship in China allows government criticism but silences collective expression. American Political Science Review, 107(2), 326-343.

King, G., Pan, J., \& Roberts, M. E. (2017). How the Chinese government fabricates social media posts for strategic distraction, not engaged argument. American Political Science Review, 111(3), 484-501.

Li, S. (2001). Zaizao yuyan [Restore language]. Zhanlue yu Guanli, 2, 110-115.

Li, C. (2009). The Chinese Communist Party: Recruiting and controlling the new elites. Journal of Current Chinese Affairs, 38(3), 13-33.

Li, T., \& Zhang, C. (2017). Shijiuda baogao "zhihui shehui" jiedu: Xi Jinping shuode "zhihuishehui" jiujing shi sha? [Interpretation of the "smart society" in the 19th National Congress: What is "smart society" according to Xi Jinping?]. Besticity. Retrieved from http://www.besticity.com/newsExpress/174629.html

Liang, J. (2018). Xi Jinping xin shidai zhongguo tese shehui zhuyi sixiang de san ge xiangdu [The three dimensions of Xi Jinping's new socialist thought with Chinese characteristics]. Cpcnews.cn. Retrieved from http://theory.people.com.cn/n1/2018/0508/ c40531-29971743.html

Manin, B. (1997). Principles of representative gouvernement. Cambridge: Cambridge University Press.

Manion, M. (2015). Information for autocrats: Representation in Chinese local congresses. Cambridge: Cam- 
bridge University Press.

Mulieri, A. (2013). Beyond electoral democracy? A critical assessment of constructivist representation in the global arena. Representation, 49(4), 515-527.

Näsström, S. (2011). Where is the representative turn going? European Journal of Political Theory, 10(4), 501-510.

Pitkin, H. (1972). The concept of representation. Berkeley, CA: University of California Press.

Renmin Ribao. (2014). Deng Xiaoing lilun zai zhongguohua makesi zhuyi Zhong de diwei he zuoyong [The status and role of the Deng Xiaoping theory in China's Marxism]. People.cn. Retrieved from http://opinion. people.com.cn/n/2014/0825/c1003-25528600.html

Renmin Ribao. (2015). Shizhong jianchi renmin liyi zhishang [Persistently uphold the interests of the people]. People.cn. Retrieved from http://opinion. people.com.cn/n/2015/0826/c1003-27516546.html

Renmin Ribao. (2016). Xi Jinping zhuchi zhaokai wangluo anquan he xinxihua gongzuo zuotanhui [General Secretary $\mathrm{Xi}$ Jinping presides at a symposium on cybersecurity and digitalization]. Cpcnews.cn. Retrieved from http://cpc.people.com.cn/n1/2016/ 0420/c64094-28289000.html

Renmin Ribao. (2018). Xi Jinping: Minrui zhuazhu xinxihua fazhan lishi jiyu, zizhu chuangxin tuijin wangluo qiangguo jianshe [Xi Jinping: A keen grasp of the historical opportunity of digitalization, independent innovation and promotion of building of cyber superpower]. Cpcnews.cn. Retrieved from http://jhsjk. people.cn/article/29941696

Repnikova, M. (2018). Media politics in China. Princeton, NJ: Princeton University Press.

Repnikova, M., \& Fang, K. (2018). Authoritarian participatory persuasion 2.0: Netizens as thought work collaborators in China. Journal of Contemporary China, 27(113), 763-779.

Rossiter, C. (1961). Federalist paper no. 10. In C. Rossiter (Ed.), The federalist papers: Alexander Hamilton, James Madison, John Jay. New York, NY: New American Library.

Salmon, N. (2011). Investigating China: What it means to be a journalist in a socialist market economy. Books \& Ideas. Retrieved from https://booksandideas.net/ Investigating-China.html

Saward, M. (2010). The representative claim. Oxford: Oxford University Press.

Schneider, F. (2018). China's digital nationalism. Oxford: Oxford University Press.

Shambaugh, D. (2008). China's Communist Party: Atrophy and adaptation. Berkeley, CA, and London: University of California Press.

Shan, Z. (2018). Dui zhihui chengshi de xin kuozhanRenmin ribao xinzhi xinjue: zhihui shehui wei shehui xinxihua zhiming fangxiang [New expansion of smart cities-New insights from People's Daily: Smart society leads the direction for the informatization of the society]. People.cn. Retrieved from http://opinion. people.com.cn/n1/2018/0124/c1003-29782429.html Shpakovskaya, A. (2018). From deputy to blogger: An empirical map of political representation in the Chinese cyberspace. Paper presented at the 17th Chinese Internet Research Conference, Leiden, The Netherlands.

Sieyes, E-J. (1789). Dire de l'Abbé Sieyès sur la question du véto royal, à la séance du 7 septembre 1789 [Abbé Sieyès on the royal veto power at the 7 September 1789 meeting]. Versailles: Baudouin.

Sintomer, Y. (2013). Les sens de la representation: Usages et mésusages d'une notion [The meaning of representation: Uses and misuses of a notion]. Raisons Politiques, 2(50), 13-34.

Sorace, C. (2017). Shaken authority: China's Communist Party and the 2008 Sichuan earthquake. Ithaca, NY: Cornell University Press.

Thornton, P. (2016). The cultural revolution as a crisis of representation. The China Quarterly, 2016(227), 697-717.

Urbinati, N., \& Warren, M. E. (2008). The concept of representation in contemporary democratic theory. Annual Review of Political Science, 11, 387-412.

Van Dijk, T. A. (1997). What is political discourse analysis? Belgian Journal of Linguistics, 11(1), 11-52.

Wang, H. (2017). Sange chuangxin zengqiang daibiao lianxi qunzhong shixiao [On how three innovations improve the linkage between representatives and people], Renda Jianshe (NPC construction), 2017(1), 31.

Wu, T. (2006). Zhongguo Gongchandang shi renmin liyide daibiao [The Chinese Communist Party is the representative of the interests of the people]. People.cn. Retrieved from http://theory.people.com.cn/ GB/49150/49151/4225675.html

Xi, J. (2017). Zai Zhongguo Gongchandang di 19 ci quanguo daibiao dahui shang de baogao [The report by Xi Jinping delivered at the 19 National Party's Congress]. People's government of the PRC. Retrieved from http://www.gov.cn/zhuanti/2017-10/ 27/content_5234876.htm

Yang, G. (2009). The power of the internet in China: Citizen activism online. New York, NY: Columbia University Press.

Zheng, Y. (2007). Technological empowerment: The internet, state, and society in China. Stanford, CA: Stanford University Press.

Zhong, Z. (2009). Zhongsu butong de gaige kaifang yuanyu butong de lilun zhidao [The different reform and opening policies between China and the Soviet Union stem from the different theoretical guidance]. People.cn. Retrieved from http://theory.people.com. $\mathrm{cn} / \mathrm{GB} / 41038 / 9368567 . \mathrm{html}$

Zhou, S. (2016). Lingdao ganbu yao xuehui tongguo wangluo zou qunzhong luxian [Leading cadres must learn to follow the mass line by means of the Internet]. People.cn. Retrieved from http://politics.people.com.cn/ n1/2016/0430/c1001-28316212.html 


\section{About the Authors}

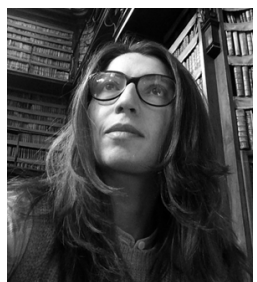

Emilie Frenkiel is an Associate Professor in Political Science at Université Paris-Est Créteil, France. She is the author of Conditional Democracy: The Intellectual Debate on Political Reform in China (ECPR, 2015). Her research interests include political representation, deliberation, political reform and participatory innovations in China, and civic tech. She is a member of the editorial boards of social science journals La Vie des Idées and Books \& Ideas.

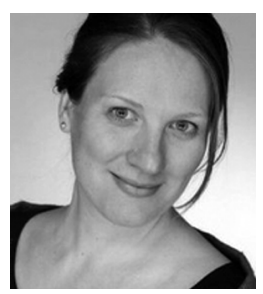

Anna Shpakovskaya $(\mathrm{PhD})$ is a Senior Research Fellow in the French-German Joint Cooperation Project "New Political Representative Claims: A Global View-France, Germany, Brazil, China, India Compared (2016-2019)". She works at the Institute of East Asian Studies, University of Duisburg-Essen, Germany. Her research interests include the theory of political representation, digitalization of political representation in China and Russia, international non-government organizations, the International Red Cross humanitarian movement, and the Chinese Red Cross. 